\title{
REGISTRATION OF TIMES OF PRESERVING THE LOWERED TEMPERATURES OF COMBUSTION PRODUCTS IN THE TRACE OF THE AEROSOL FLOW
}

\author{
Ivan S. Vojtkov ${ }^{1}$, Roman S. Volkov ${ }^{1,}$, and Galina A. Chernova ${ }^{1}$ \\ ${ }^{1}$ National Research Tomsk Polytechnic University, 634050 Tomsk, Russia
}

\begin{abstract}
This study examines the traces of water droplets moving through high-temperature combustion products (initial temperatures are $430-950 \mathrm{~K})$. The temperature of a gas-vapor mixture in the area of droplets' traces is measured using low-inertia thermocouples (thermal lag is less than $0.1 \mathrm{~s}$ ). The experiments revealed that the temperature in the trace of water droplets is significantly reduced (from $15 \mathrm{~K}$ to $140 \mathrm{~K}$ ) even when using an aerosol flow with small droplets. The experiments showed that the times of keeping low temperatures in the trace of water droplets may reach $30 \mathrm{~s}$.
\end{abstract}

\section{Introduction}

Active development of different industries is inevitably accompanied with the growth of the number of fires and fires in factories, which often cause the most disastrous consequences. These industries primarily include oil and gas production, refineries and energy complexes. Therefore, the issues of fire safety in such enterprises are very important: rules and requirements for personnel are tightened, modern automatic fire extinguishing system based on the microprocessor are implemented, various methods for the elimination of fires and delivery of quenching compounds in the fire zone are offered.

Application of sprayed water for fire localization and liquidation is one of the most common methods of firefighting nowadays. Fire-extinguishing system based on water mist are developed, tested and put into operation. However, there is no an accurate information about the experimental ranges of the temperature of the combustion products when they are impacted by a stream of droplets. So, there is an interest in experimental research of temperature changing of combustion products process in the steam-dripping flow wake.

The purpose of this work - experimental investigation of changing of the combustion products temperature in the trace of a droplet aerosol flow when it moves into the fire.

\footnotetext{
*Corresponding author: romanvolkov@tpu.ru
} 


\section{The methods and the experimental setup}

In experimental studies, a setup (similar to $[1,2]$ ) equipped with high-speed video recording tools (cameras Phantom V411 and Phantom Miro M310, frame rate is up to $6 \cdot 10^{5}$ fps, maximum recording resolution is $1280 \times 1280$ pix), and a cross-correlation software and hardware complex (double-pulse solid-state Nd:YAG laser Quantel EverGreen 70) was used. The scheme of the experiment is shown at fig. 1.

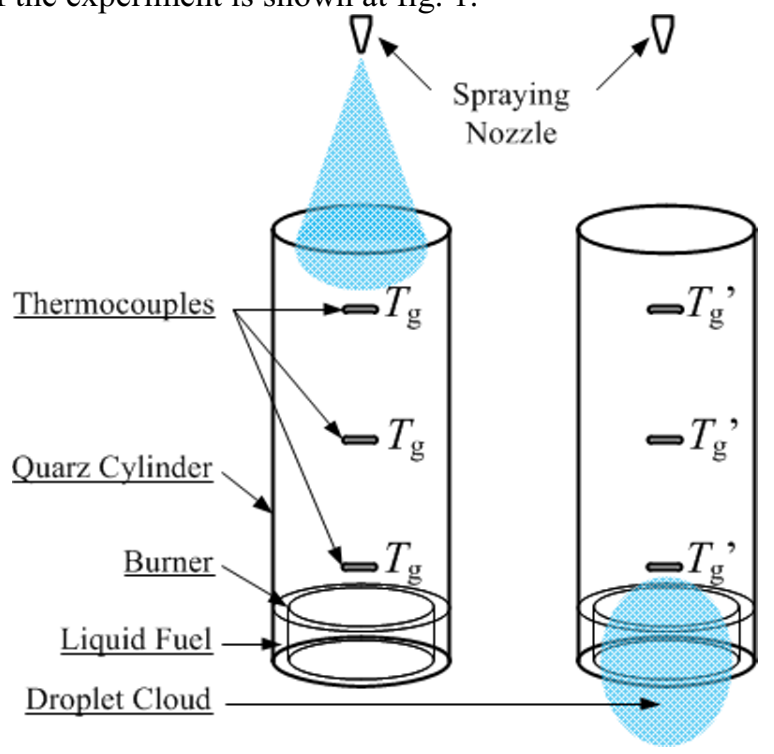

Fig. 1. Scheme of the experiment.

Combustion products were generated as follows. Burner (fig. 1) was filled with fuel in an amount of $250 \mathrm{ml}$. The ignition of fuel was initiated using a piezoburning system. Glass cylinder was installed to burner. Thus, the upward flow of the kerosene combustion products was formed inside the cylinder.

Thermocouples of type $\mathrm{K}$ (for $T_{\mathrm{g}}$ registration) (see fig. 1) were placed at the three points over the height of cylindrical channel (at distances of $0.12,0.4$, and $0.7 \mathrm{~m}$ from burner base) on its axis of symmetry.

To generate the droplet cloud, a system was used consisting of tank with water (liquid pressure is $100-300 \mathrm{kPa}$ depending on the experimental conditions), water supply channel, and a set of spray nozzles (fig. 1). We used three types of spray nozzles for generation of different (by range of particle sizes) drip flows: $R_{\mathrm{d}}=0.08-0.35 \mathrm{~mm}$ - large droplets; $R_{\mathrm{d}}=0.06-0.18 \mathrm{~mm}$ - average droplets; and $R_{\mathrm{d}}=0.04-0.12 \mathrm{~mm}$ - fine spray. The initial velocities $\left(U_{\mathrm{d}}\right)$ of the drip flow varied in the range of $1-3 \mathrm{~m} / \mathrm{s}$ in the experiments. The volume concentration of droplets in the sprayed flow $\left(\gamma_{\mathrm{d}}\right)$ varied in the range of $3.8 \cdot 10^{-5}$ $10.3 \cdot 10^{-5}\left(\mathrm{~m}^{3}\right.$ of water $) /\left(\mathrm{m}^{3}\right.$ of gas). For this purpose, several (up to three) spray nozzles were used simultaneously to provide the same range of change in droplets sizes.

A type-L thermocouple (temperature measurement range is $273-473 \mathrm{~K}$, systematic error is $\pm 1.5 \mathrm{~K}$, thermal lag is less $10 \mathrm{~s})$ monitored the initial water temperature $\left(T_{\mathrm{w}}\right)$ which was maintained at $300 \mathrm{~K}$ by a set of built-in heating elements in tank 8 . The maximum random error in measuring the temperature $T_{\mathrm{w}}$ was $3 \mathrm{~K}, T_{\mathrm{g}}-15 \mathrm{~K}$.

To determine the initial droplet flow velocities $\left(U_{\mathrm{d}}\right)$, PIV [3] and PTV [4] methods were used. The PIV method was used for processing the videograms of the drip flow at the input 
of cylindrical channel 12. The PTV method was used for the videograms captured at the output of the cylindrical channel. The SP method [5] was used to estimate the initial sizes of water droplets. The droplet flow was monitored at two points: at the input and output of cylindrical channel (see fig. 1). For this, the experimental setup was equipped with diffuse screens, which were connected to Nd:YAG laser via optical fibers. Procedures for measuring velocities $U_{\mathrm{d}}$ and sizes $R_{\mathrm{d}}$ were performed simultaneously.

The error in determining $U_{\mathrm{d}}$ using this approach did not exceed $2 \%$. Systematic error in determining droplet sizes by the SP method was defined using the scale factor $(S)$ and did not exceed $3.5 \%$ in the experiments.

The following parameters were determined after each experiment: $\Delta T_{\mathrm{g}}$ - temperature reduction of combustion products in the wake of the drip flow with respect to its initial values, $K ; \tau$ - time of keeping low temperatures (relative to initial ones) of combustion products in the wake of the moving liquid (a time interval from the beginning of temperature reduction of combustion products until the complete temperature recovery to the initial value). The error in determining the times $\tau$ did not exceed $1 \mathrm{~s}$.

\section{Results of research}

Temperature recovery times $(\tau)$ in the trace of droplet cloud obtained during the processing of the result of experimentation are presented in the Table 1. Established that primary droplet size exert determining influence on the intensity of the temperature drop in the trace of droplet cloud. Most time value of temperature recovery to datum value was observed at relative large liquid spray $\left(R_{\mathrm{d}}=0.08-0.35 \mathrm{~mm}\right)$. For the other two types of spray can be noted minor differences times $\tau$ (in the range of $8-10 \%$ ), which is likely caused by a close range drop size change in the stream of data types of the liquid spray: $R_{\mathrm{d}}=0.06-0.18 \mathrm{~mm}$ middle and $R_{\mathrm{d}}=0.04-0.12 \mathrm{~mm}$ - small, respectively.

Table 1. Time values $(\tau)$ of temperature recovery to datum value (to water injection) in the trace of droplet cloud.

\begin{tabular}{|c|c|c|c|c|}
\hline Droplet size, $\mathbf{~ m m}$ & $\boldsymbol{T}_{\mathbf{g}}=\mathbf{4 5 0} \mathbf{~ K}$ & $\boldsymbol{T}_{\mathbf{g}}=\mathbf{5 5 0} \mathbf{~ K}$ & $\boldsymbol{T}_{\mathbf{g}}=\mathbf{6 5 0} \mathbf{~ K}$ & $\boldsymbol{T}_{\mathbf{g}}=\mathbf{7 5 0} \mathbf{~ K}$ \\
\hline $0.08<R_{\mathrm{d}}<0.35$ & $\tau \approx 16.5 \mathrm{~s}$ & $\tau \approx 19.5 \mathrm{~s}$ & $\tau \approx 22 \mathrm{~s}$ & $\tau \approx 24 \mathrm{~s}$ \\
\hline $0.06<R_{\mathrm{d}}<0.18$ & $\tau \approx 16.5 \mathrm{~s}$ & $\tau \approx 18 \mathrm{~s}$ & $\tau \approx 19 \mathrm{~s}$ & $\tau \approx 20 \mathrm{~s}$ \\
\hline $0.04<R_{\mathrm{d}}<0.12$ & $\tau \approx 17.5 \mathrm{~s}$ & $\tau \approx 19 \mathrm{~s}$ & $\tau \approx 20 \mathrm{~s}$ & $\tau \approx 21 \mathrm{~s}$ \\
\hline
\end{tabular}

Fig. 2 presents time values of saved low temperature $(\tau)$ in the trace of droplet cloud depending on temperature of combustion products which was result of data processing. The fig. 2 shows that peak value time of recovery $(\tau \approx 24 \mathrm{~s})$ characteristic of the droplet size 0.25 $\mathrm{mm}$ and peak value of the combustion products temperature $850 \mathrm{~K}$.

This result is explained as follows. Droplets with size more than $0.17 \mathrm{~mm}\left(R_{\mathrm{d}}>0.17\right.$ $\mathrm{mm}$ ) are evaporated by $20-40 \%$ [6] passing through combustion products 1 meter thereby contributing to lowering of combusting products temperature by two mechanism: lowering flames and combustion products temperature by evaporating (endothermic phase transformation with intense absorption of energy); supplantation oxidants and combustion products from combustion zone by the formed water vapor.

Fig. 2 clearly shows that for all the above types of spray value $\tau$ are comparable and differ by no more than $1.5-2 \mathrm{~s}$ at temperature gas environment $400-500 \mathrm{~K}$. It is obvious that at these temperatures of combustion products is realized the first mechanism to reduce the flame temperature. At temperatures above $550 \mathrm{~K}$, a significant difference in values $\tau$, which is especially noticeable when the $T_{\mathrm{g}}$ values of $850 \mathrm{~K}$ (fig. 2). 


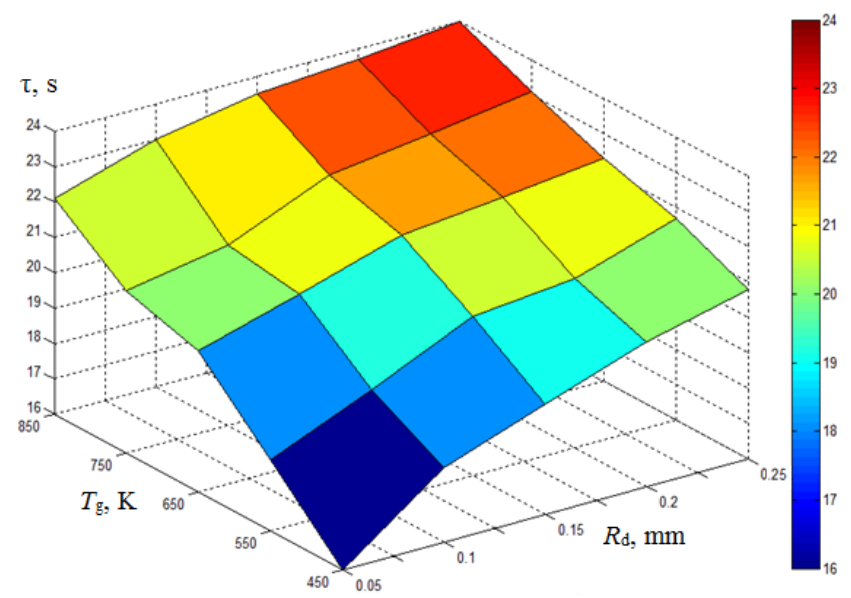

Fig. 2. 3D-diagram time of saving low temperature in the race of droplet cloud depending on droplet size in the aerosol flow at different combustion products temperature and concentration drops in aerosol $\left(\gamma \approx 7.1 \cdot 10^{-5}\left(\mathrm{~m}^{3}\right.\right.$ of water $) /\left(\mathrm{m}^{3}\right.$ of gas $\left.) ; U_{\mathrm{g}} \approx 0.8 \mathrm{~m} / \mathrm{s} ; T_{\mathrm{w}} \approx 300 \mathrm{~K}\right)$.

This result is due to the fact that droplet sizes $R_{\mathrm{d}}<0.16 \mathrm{~mm}$ can be completely evaporated by passing a distance of $1 \mathrm{~m}$ in the high-temperature combustion products [1, 2 ]. Thus, there is a decrease in temperature of the combustion products at the expense of the flame energy costs for the phase transition (evaporation).

\section{Conclusion}

The experiments identified ranges of temperature change, as well as the value of time saving low temperature of the combustion products in the trace of a drop flow. Define values of the time $\tau$ for different values of temperature $T_{\mathrm{g}}$, and droplet sizes $R_{\mathrm{d}}$ and temperature of combustion products can be used for making a choose of sprayers operation condition in water mist fire suppression systems. Using these results we can predict conditions that ensure the effective reduction of combustion products temperature.

\section{Acknowledgments}

The investigation was supported by Russian Science Foundation (project 14-39-00003).

\section{References}

1. R.S. Volkov, G.V. Kuznetsov, P.A. Strizhak, Int. J. Heat Mass Transfer 96 (2016)

2. R.S. Volkov, G.V. Kuznetsov, J.C. Legros, P.A. Strizhak, Int. J. Heat Mass Transfer 95 (2016)

3. J.V. Simo Tala, S. Russeil, D. Bougeard, J.-L. Harion, Exp. Therm. Fluid Sci. 50 (2013)

4. Y. Hagiwara, S. Sakamoto, M. Tanaka, K. Yoshimura, Exp. Therm. Fluid Sci. 26, 2 (2002)

5. S. Dehaeck, H. Van Parys, A. Hubin, J.P.A.J. Van Beeck, Exp. Fluids 47, 2 (2009)

6. O.V. Vysokomornaya, G.V. Kuznetsov, P.A. Strizhak, J. Eng. Phys. Thermophys. 89, $1(2016)$ 